\title{
False selection of syringe-brand compatibility and the method of correction during target-controlled infusion of propofol
}

\author{
Yun-Jeong Chae, Jong-Yeop Kim, Do-Won Kim, Bong-Ki Moon, and Sang-Kee Min \\ Department of Anesthesiology and Pain Medicine, Ajou University School of Medicine, Suwon, Korea
}

Background: We evaluated volumetric differences of syringe brand compatibilities, and investigated the impact of false brand settings on target-controlled infusion (TCI) and their methods of correction.

Methods: Gravimetric measurement of $10 \mathrm{ml}$ bolus infusions was performed using BD Plastipak (BDP) and Terumo compatible syringes, while setting to 7 different kinds of brand compatibilities (BDP, Sherwood Monoject, BD Perfusion, Braun Perfusor, Braun Omnifix, Fresenius Injectomat, and Terumo). To investigate the performance of TCI using BDP with a false setting to Terumo ( $\mathrm{BDP}_{\text {TERUMO }}$ ) and Terumo to BDP (TERUMO ${ }_{\mathrm{BDP}}$ ), 24 TCI targeting 4.0 $\mu \mathrm{g} / \mathrm{ml}$ of effect-site concentration $\left(\mathrm{C}_{\text {eff }}\right)$ of propofol were performed. Subsequently, another 24 TCI were evaluated for simple corrections of false settings at $30 \mathrm{~min}$. We also investigated 24 TCI using active corrections (fill-up for $\mathrm{BDP}_{\text {TERUMO }}$, evacuation for TERUMO ${ }_{\mathrm{BDP}}$ ) based on the pharmacokinetics of propofol. The $\mathrm{C}_{\text {eff }}$ at $30 \mathrm{~min}$ of $\mathrm{TCI}$ and time to normalize to $\pm 5 \%$ of target concentration $\left(\mathrm{T}_{ \pm 5 \% \text { target }}\right)$ were compared.

Results: The $\mathrm{C}_{\text {eff }}$ of $\mathrm{BDP}_{\text {TERUMO }}$ showed negative bias and $17.2 \%$ inaccuracy, and the $\mathrm{C}_{\text {eff }}$ of TERUMO $\mathrm{BDP}_{\text {B }}$ showed positive bias and $19.5 \%$ inaccuracy. The $\mathrm{C}_{\text {eff }}$ at $30 \mathrm{~min}$ showed no difference between the methods of correction in $\mathrm{BDP}_{\text {TERUMO }}$ or TERUMO $\mathrm{BDP}_{\text {. }}$. The $\mathrm{T}_{ \pm 5 \% \text { target }}$ in both the active corrections was significantly shorter than that of each simple corrections $(\mathrm{P}<0.001)$.

Conclusions: False brand setting of syringe proportionally maintained different predicted concentrations as much as the volumetric differences of syringe brand. Based on the results, it is proposed that correction methods based on pharmacokinetics could effectively normalize the differences, without giving up the wrong TCI. (Korean J Anesthesiol 2013; 64: 251-256)

Key Words: Propofol, Syringe, Target-controlled infusion, Volumetric differences.

Received: September 14, 2012. Revised: November 14, 2012. Accepted: December 4, 2012.

Corresponding author: Sang-Kee Min, M.D., Department of Anesthesiology and Pain Medicine, Ajou University School of Medicine, San 5, Wonchon-dong, Yeongtong-gu, Suwon 443-721, Korea. Tel: 82-31-219-5572, Fax: 82-31-219-5579, E-mail: anesmin@naver.com

(c) This is an open-access article distributed under the terms of the Creative Commons Attribution Non-Commercial License (http:// creativecommons.org/licenses/by-nc/3.0/), which permits unrestricted non-commercial use, distribution, and reproduction in any medium, provided the original work is properly cited. 


\section{Introduction}

Disposable syringes have brand specific size and length, and the operator's manual for the syringe pump recommends a brand-specific setting for accurate infusion. So far, many advances in functional efficacy and safety of syringe pumps have been achieved [1,2]; however, most syringe pumps are not always able to automatically detect of all syringe brands and their compatibilities. Therefore, in a situation where various syringe pumps and various brands of syringe are furnished together in the same anaesthetic unit, false setting of brand compatibility might occur, and the errors could be recognized after commencement of infusion, or might possibly be neglected.

Diprifusor $^{\odot}$, the first generation of commercial targetcontrolled infusion (TCI), is exclusive only for Diprivan ${ }^{\circledR}$ PFS (propofol prefilled-syringe), which has an automatically recognizing security tag system using a radio-frequency technology [3]. However, infusion devices equipped with such an automatic recognition system are very limited. Therefore, vigilance must be exercised during the preparation of TCI.

Accordingly, we attempted to evaluate the volumetric distinctions of syringe brand compatibilities, and the impact of false setting of brand on TCI of propofol. Furthermore, we also investigated the methods for correction of these error settings in the middle of TCI of propofol.

\section{Materials and Methods}

To compare the volumetric differences between syringe brands, BD Plastipak compatible $60 \mathrm{ml}$ syringes (BDP) (BD 60 ml Syringe, Luer-Lok ${ }^{\mathrm{TM}}$ Tip, BD, USA) or Terumo compatible $50 \mathrm{ml}$ syringes (TERUMO) (Kovax-Syringe ${ }^{\circledR} 50 \mathrm{ml}$, Korea Vaccine Co., LTD, Republic of Korea) were placed into syringe pumps (PILOTE ANESTHESIE 2 IS ${ }^{\circledR}$, Fresenius Vial, Le Grand Chemin, Brezins, France), and 7 brand compatibilities (BD Plastipak, Sherwood Monoject, BD Perfusion, Braun Omnifix, Braun Perfusor, Fresenius Injectomat, and Terumo) were randomly selected. Three syringe pumps were randomly used, and prior to this study, syringe pumps were calibrated; zero calibration for $6.0 \pm 0.05 \mathrm{~V}$, and pressure calibration at 0.8 bar. All randomizations were performed using the Microsoft ${ }^{\circledR}$ Excel randomization function.

The schematic assembly used for the determination of volumetric differences and TCI experiments is illustrated in Fig. 1. The tip of the syringe was connected to a 3-way stopcock, while one male-side was used for fluid evacuation and the other maleside was connected to low-compliance $200 \mathrm{~cm}$ syringe infusion lines (Injectomat Line ${ }^{\circledR}$, Fresenius Kabi AG, Bad Homburg, Germany). The distal tip of infusion line was connected to an 18-gauge intravenous indwelling cannula (Introcan ${ }^{\circledR}$ Certo, B. Braun, Melsungen AG, Germany), and the cannula tip was submerged $0.5 \mathrm{~cm}$ into water in a sampling glass. To prevent natural evaporation, a thin layer of oil was spread on the surface of water. To minimize fluid-shift during the procedure, the tip of the syringe was maintained at the same height with the water surface in a sampling glass before the start of infusion. Careful endeavors were made to fill the infusion assembly with distilled water without air. After purging the line and evacuating $2 \mathrm{ml}$ of infusate [4], $10 \mathrm{ml}$ of bolus was administered, and the infused amount was gravimetrically measured using an electric microbalance (FX-300i, A\&D Co, Ltd, Republic of Korea), which has a sensitivity of $0.001 \mathrm{~g}$. The weight was converted to volume delivery assuming a conversion of $1 \mathrm{~g}$ of distilled water equaling $1.0029 \mathrm{ml}$, while water temperature was maintained within $23-25^{\circ} \mathrm{C}$. Total 168 measurements ( 2 syringe types $\times 7$ brands $\times 12$ times $=168)$ were performed. The percentage differences

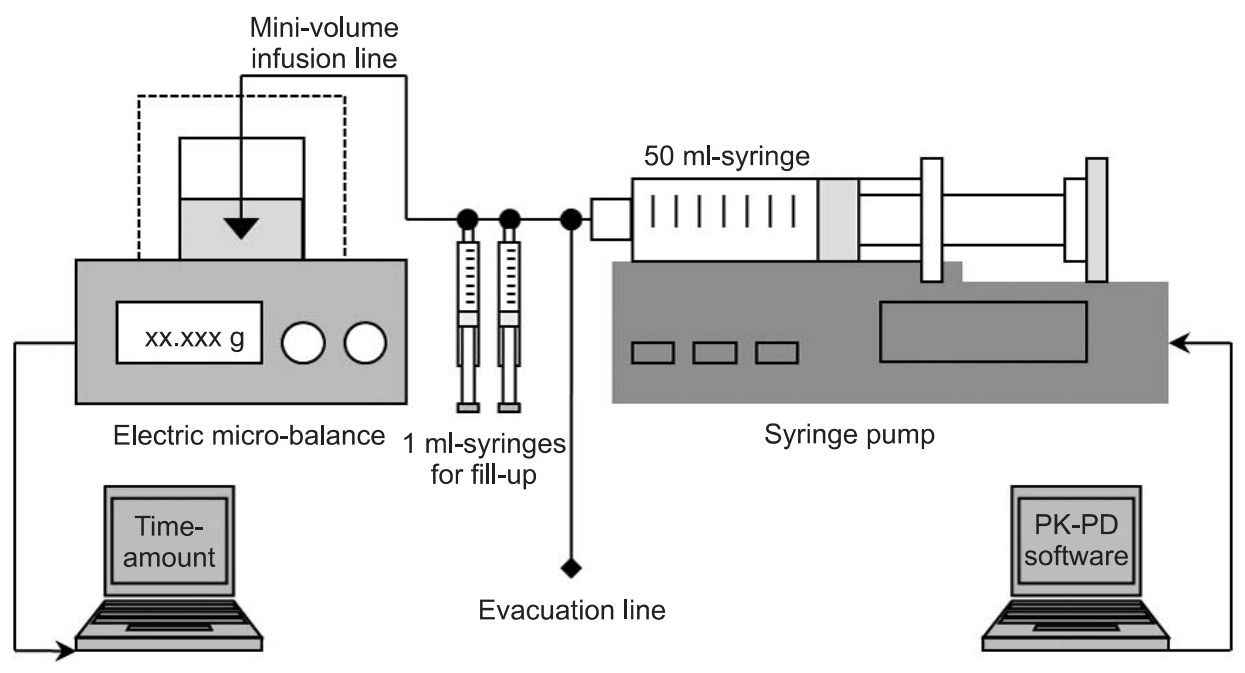

Fig. 1. The schematic infusion assembly used for the determination of volumetric differences between the syringe brand compatibilities and TCI experiments for the corrections of the false setting of syringe compatibilities. 
between the measured and nominal bolus are illustrated in Table 1. Maximal differences occurred in cases of BDP with false setting to Terumo $(-16.3 \%)\left(\mathrm{BDP}_{\text {TERUMO }}\right)$, and TERUMO with false setting to BD Plastipak $(+19.7 \%)\left(\right.$ TERUMO $\left._{\mathrm{BDP}}\right)$. Therefore, false settings between BDP and TERUMO had been decided to evaluate during TCI.

Main TCI experiments were conducted, using sterile distilled water as a virtual solution for $2.0 \%$ propofol. TCI was targeted to $4.0 \mu \mathrm{g} / \mathrm{ml}$ of effect site concentration $\left(\mathrm{C}_{\text {eff }}\right)$ using the TCI software (Asan pump ${ }^{\odot}$, version 2.0.2, Bionet Co., Ltd., Seoul, Republic of Korea) and the syringe pump described above. The pharmacokinetic (PK) model of Gepts et al. [5], and 1.21 $/$ min of $k_{\text {e0 }}$ [6] were used in the present study. Body weight was randomly used at $2.5 \mathrm{~kg}$ intervals, between 50 to $80 \mathrm{~kg}$. After every installation of syringe or brand corrections, $2 \mathrm{ml}$ of infusate was evacuated into the atmosphere while pressing the purge button [4]. TCI was maintained until $90 \mathrm{~min}$, or until when an 'end of infusion alarm' was triggered. All TCI data files including the plasma concentration $\left(\mathrm{C}_{\mathrm{p}}\right)$ and $\mathrm{C}_{\text {eff }}$ were saved on

Table 1. Percentage Differences (\%) between the Nominal and Measured Bolus after Administration of $10 \mathrm{ml}$ Bolus using BD Plastipak and Terumo Compatible Syringes with 7 Different Brand Compatibilities

\begin{tabular}{lcc}
\hline & $\begin{array}{c}\text { BD Plastipak } \\
\text { compatible syringe }\end{array}$ & $\begin{array}{c}\text { Terumo } \\
\text { compatible syringe }\end{array}$ \\
\hline Terumo & $-16.3 \pm 0.40$ & $-0.3 \pm 0.35$ \\
Fresenius Injectomat & $-15.3 \pm 0.36$ & $0.8 \pm 0.42$ \\
Braun Perfusor & $-8.9 \pm 0.42$ & $8.5 \pm 0.44$ \\
Braun Omnifix & $-8.6 \pm 0.25$ & $9.0 \pm 0.42$ \\
BD Perfusion & $-8.6 \pm 0.42$ & $8.9 \pm 0.37$ \\
Sherwood Monoject & $0.2 \pm 0.36$ & $19.2 \pm 0.37$ \\
BD Plastipak & $0.3 \pm 0.44$ & $19.7 \pm 0.35$ \\
\hline
\end{tabular}

Values indicate mean \pm SD. hard-disk. On all occasions of gross leakage of fluid from the infusion assembly, air delivery into the sampling glass on visual inspection, and data communication error in the personal computer due to a syringe pump or the microbalance, the experiment was discarded and implemented again from the first step. During TCI, the cumulative weights of delivered infusate were also gravimetrically measured and saved as Microsoft Excel $^{\circledR}$ spreadsheet using RS232 interface software (RrKey Ver. 1.34, A\&D Co, Ltd., Republic of Korea). Each spreadsheet was converted into a file formatted for the pharmacokinetic/ pharmacodynamic (PK/PD) software (STANPUMP ${ }^{\odot}$, written by Steven L. Shafer, Palo Alto, CA, USA) simulations, which reproduced the actual time courses of $\mathrm{C}_{\mathrm{p}}$ and $\mathrm{C}_{\text {eff }}$.

First, we performed 24 TCIs without any brand correction, and 48 TCIs with simple and active corrections. For simple corrections, twenty-four TCIs were randomly performed using $\mathrm{BDP}_{\text {TERUMO }}$ and TERUMO $\mathrm{BDP}_{\mathrm{P}}$ and infusion was stopped at $30 \mathrm{~min}$. After that, false brand setting was corrected, and duration of correction was limited to $1 \mathrm{~min}$. For active corrections, twentyfour TCIs were also randomly performed using $\mathrm{BDP}_{\text {TERUMO }}$ and TERUMO $_{\mathrm{BDP}}$. Active corrections were performed at $30 \mathrm{~min}$ after the start of TCI, which were composed of three steps; (1) Estimation of bolus amount or evacuation time, (2) Adjustment of infusion, and (3) Brand correction. The median maintenance concentrations during 'TCI without correction' were used as a reference value for the actual predicted concentration of the wrong TCI. The methods were a fill-up correction for $\mathrm{BDP}_{\text {TERUMO }}$ and an evacuation correction for TERUMO ${ }_{\mathrm{BDP}}$. Typically, two $1 \mathrm{ml}$-syringes for a fill-up correction and a evacuation line were connected in the middle of the infusion lines (Fig. 1). The precise time courses of active corrections are summarized in Table 2.

Table 2. Processes of Active Corrections for the $\mathrm{BDP}_{\text {TERUмо }}$ and TERUMO ${ }_{\mathrm{BDP}}$ during Targeting $4.0 \mu \mathrm{g} / \mathrm{ml}$ of Effect-site Concentration of Propofol, at the Time from the Start of Correction

\begin{tabular}{|c|c|c|c|}
\hline \multirow{2}{*}{$\begin{array}{l}\text { Time } \\
(\min )\end{array}$} & $\mathrm{BDP}_{\text {TERUMO }}$ & \multirow{2}{*}{$\begin{array}{l}\text { Time } \\
(\min )\end{array}$} & TERUMO $_{\text {BDP }}$ \\
\hline & $\begin{array}{l}\text { Fill-up bolus for } 4.0 \text { to } \\
4.69 \mu \mathrm{g} / \mathrm{ml} \text { of } C_{\text {eff }}\end{array}$ & & $\begin{array}{l}\text { Evacuation time for } 4.0 \text { to } \\
3.35 \mu \mathrm{g} / \mathrm{ml} \text { of } C_{\text {eff }}\end{array}$ \\
\hline \multirow[t]{2}{*}{0.0} & $\begin{array}{l}\text { Increase target to } 4.69 \mu \mathrm{g} / \mathrm{ml} \text {. } \\
\text { Calculate fill-up bolus. }\end{array}$ & 0.0 & $\begin{array}{l}\text { Turn stopcock to evacuation line } \\
\text { Evacuation of excessive infusion. }\end{array}$ \\
\hline & Decrease target to $4.0 \mu \mathrm{g} / \mathrm{ml}$. & 1.84 & Change syringe*. \\
\hline 3.5 & $\begin{array}{l}\text { Wait until equilibrium state. } \\
\text { Turn stopcock and Evacuation. } \\
\text { Inject fill-up bolus manually. }\end{array}$ & & $\begin{array}{l}\text { Barrel crasp: open and close. } \\
\text { Correct the brand. } \\
\text { Purge the syringe. }\end{array}$ \\
\hline 4.5 & $\begin{array}{l}\text { Change syringe*. } \\
\text { Barrel crasp: open and close. } \\
\text { Correct the brand. } \\
\text { Purge the syringe. } \\
\text { Turn stopcock to main stream. }\end{array}$ & 2.84 & $\begin{array}{l}\text { Turn stopcock to main stream. } \\
\text { Start infusion. }\end{array}$ \\
\hline 5.5 & Start infusion. & & \\
\hline
\end{tabular}

$\mathrm{BDP}_{\text {TERUMO }}$ : BD Plastipak syringe with false setting to Terumo, $\mathrm{TERUMO}_{\mathrm{BD}}$ : Terumo syringe with false setting to BDP, $\mathrm{C}_{\text {eff }}$ : effect-site concentration. *An activation of the function key of the software. 
To evaluate the methods between each correction, $\mathrm{C}_{\text {eff }}$ at 30 min after the start of TCI, and time to normalize within $\pm 5 \%$ of target concentration $\left(\mathrm{T}_{ \pm 5 \% \text { target }}\right)$ were compared between simple and active corrections. The amounts between fill-up bolus and evacuation during the active corrections were also compared.

Data are expressed as mean \pm standard deviation. The volumetric difference between syringe brands was compared in the one-way analyses of variance. Post hoc analyses were carried out using Scheffe's adjustment for multiple comparisons. Continuous variables between the methods of corrections were compared using an independent t-test. A value of $\mathrm{P}<0.05$ was considered significant. Statistical calculations were performed using SPSS 13.0 for windows (SPSS Inc, Chicago, IL, USA).

\section{Results}

The percentage differences between the nominal and
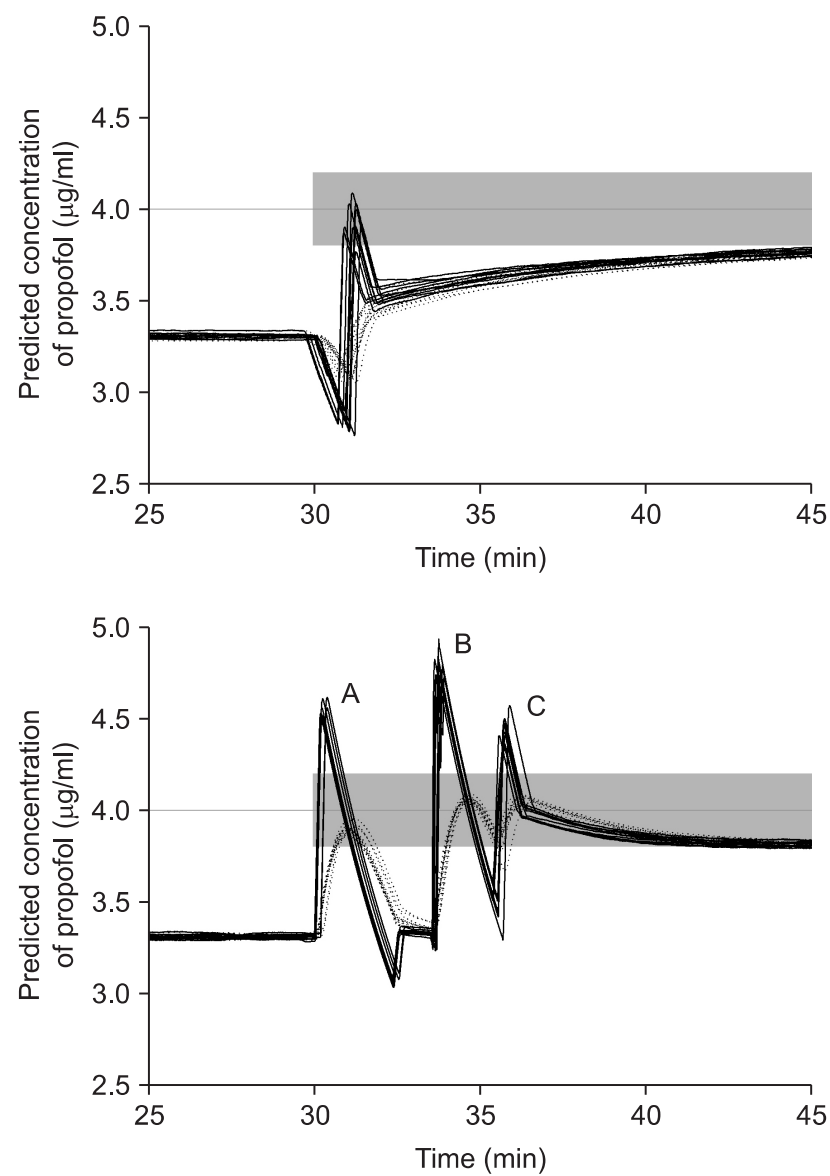

Fig. 2. Time-courses of the reproduced actual plasma (solid lines) and the effect-site (dotted lines) concentrations during the targetcontrolled infusion of propofol using the BD Plastipak syringe with false setting to Terumo. Simple (upper graph) and active (lower graph) corrections were performed at $30 \mathrm{~min}$ (Peak A = the test increase, Peak $\mathrm{B}=$ the manual fill-up bolus, Peak $\mathrm{C}=$ the syringe replacement). measured bolus after administration of $10 \mathrm{ml}$ bolus using BD Plastipak and Terumo compatible syringes with 7 different brand compatibilities are summarized at Table 1 . The median maintenance, $\mathrm{C}_{\text {eff }}$ was $3.31 \mu \mathrm{g} / \mathrm{ml}$ during $\mathrm{BDP}_{\text {TERUMO }}$ without correction, which indicated that the $\mathrm{C}_{\text {eff }}$ of $\mathrm{BDP}_{\text {TERUMO }}$ showed negative bias and $17.2 \%$ inaccuracy. And the median maintenance, $\mathrm{C}_{\text {eff }}$ was $4.78 \mu \mathrm{g} / \mathrm{ml}$ during TERUMO ${ }_{\text {вDP }}$ without correction, which indicated that the $\mathrm{C}_{\text {eff }}$ of TERUMO $\mathrm{BDP}_{\mathrm{BD}}$ showed positive bias and $19.5 \%$ inaccuracy. Time courses of $C_{p}$ and $\mathrm{C}_{\text {eff }}$ during TCI with correction are illustrated in Fig. 2 and 3 (Data from 25 to $45 \mathrm{~min}$ were demonstrated for a close look), respectively. Gray bands indicate the range of $\pm 5 \%$ target of actual predicted concentration.

During TCIs with corrections, the $\mathrm{C}_{\text {eff }}$ at $30 \mathrm{~min}$ was not different between simple and active correction in $\mathrm{BDP}_{\text {TERUMO }}$ or in TERUMO $_{\mathrm{BDP}}$, and active corrections led to a faster $\mathrm{T}_{ \pm 5 \% \text { target }}$ than simple corrections (all $\mathrm{P}<0.001$ ) (Table 3). During the fill-up correction of $\mathrm{BDP}_{\text {TERUM }}$ (Fig. 2, lower graph), the test
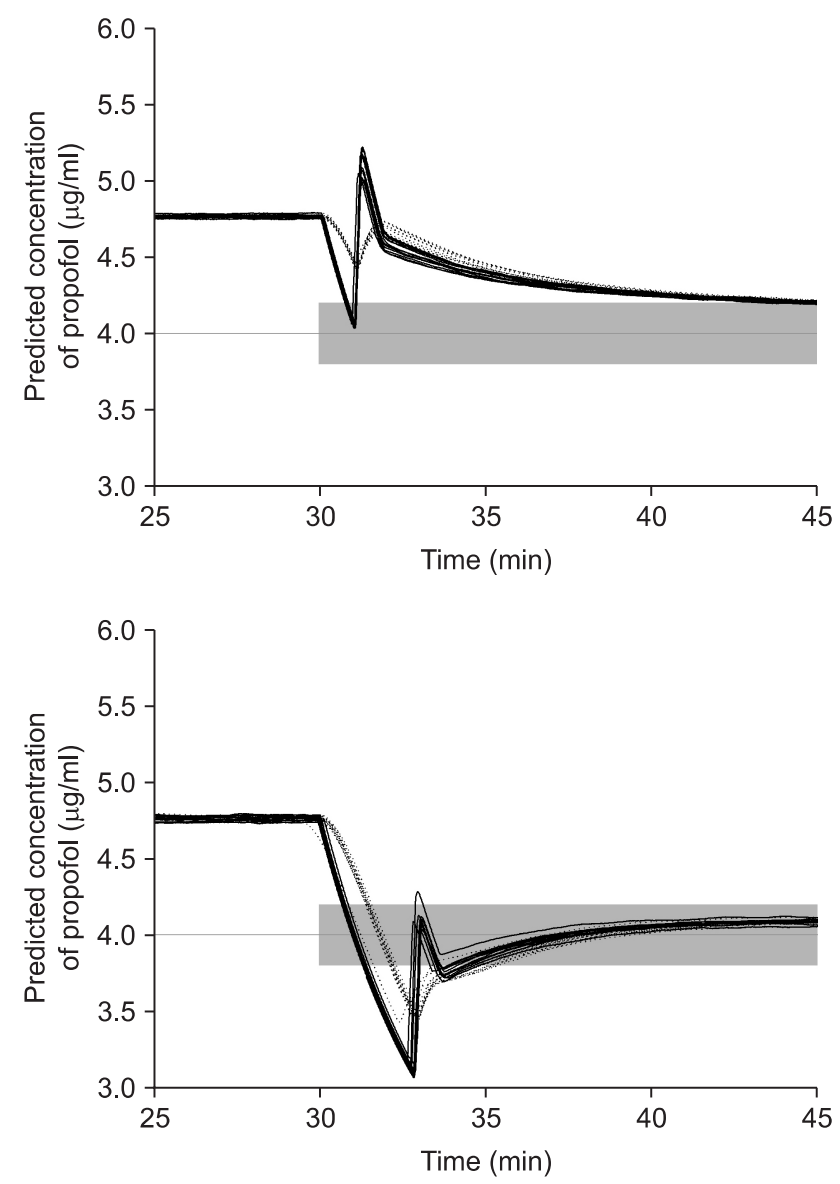

Fig. 3. Time-courses of the reproduced actual plasma (solid lines) and the effect-site (dotted lines) concentrations during the targetcontrolled infusion of propofol using the Terumo syringe with false setting to BD Plastipak. Simple (upper graph) and active (lower graph) corrections were performed at $30 \mathrm{~min}$. 
increase led to the actual $\mathrm{C}_{\text {eff }}$ to $3.89 \pm 0.026 \mu \mathrm{g} / \mathrm{ml}$ (Fig. 2, lower graph, Peak A), and the estimated fill-up bolus was $23.4 \pm 3.7$ $\mathrm{mg}$ (min-max; 18.9-29.5 mg); therefore, $1.17 \pm 0.19 \mathrm{ml}$ of $2.0 \%$ virtual propofol was manually injected, which led $\mathrm{C}_{\text {eff }}$ to 4.06 $\pm 0.012 \mu \mathrm{g} / \mathrm{ml}$ (Fig. 2, lower graph, Peak B). During evacuation correction of TERUMO ${ }_{\mathrm{BDP}}$ (Fig. 3), the actual $\mathrm{C}_{\text {eff }}$ decreased to $3.99 \pm 0.03 \mu \mathrm{g} / \mathrm{ml}$ after evacuation; however, the $C_{p}$ was $3.54 \pm$ $0.03 \mu \mathrm{g} / \mathrm{ml}$ at this moment. The evacuation amount was $23.1 \pm$ $3.2 \mathrm{mg}$ (min-max; 17.7-27.6 mg), and was not different from the fill-up bolus $(\mathrm{P}=0.831)$.

\section{Discussion}

The disposable syringe has a brand-specific intra-barrel diameter, and the syringe pump simply pushes the plunger to move linearly according to the selected brand compatibility. The pharmacokinetics of propofol are known to be linear over various infusion rates [5]. Thus, error settings of brand compatibility lead to proportional differences in predicted concentration. We had anticipated that simple brand corrections could normalize these wrong TCIs. However, it took time to normalize, and TCI could not afford accurate information on the predicted concentration during this period of normalization. Therefore, we investigated more rapid corrections, and established the principles of the correction method. First, we excluded any method using complex calculations; however, we attempted to use real-time information available from the running TCI. Second, the order of sequences was determined as follows: Testing estimation Adjusting infusion - Brand correction. Third, each sequence was attempted at the equilibrium state to validate the methods, especially during the fill-up correction.

The median maintenance $\mathrm{C}_{\text {eff }}$ of $\mathrm{BDP}_{\text {TERUMO }}$ was $3.31 \mu \mathrm{g} /$ $\mathrm{ml}$, and the amount to increase from 3.31 to $4.0 \mu \mathrm{g} / \mathrm{ml}$ was considered to be identical to the amount to increase from 4.0 to $4.69 \mu \mathrm{g} / \mathrm{ml}$. Therefore, after a test increase to $4.69 \mu \mathrm{g} / \mathrm{ml}$, the infused amount for the increase in $\mathrm{C}_{\text {eff }}$ on the display screen was calculated. However, the syringe brand had not yet been corrected; therefore, it was actually increased to $3.89 \mu \mathrm{g} / \mathrm{ml}$ (Fig. 2, lower graph, Peak A). Subsequently, manual fill-up bolus led to $4.06 \mu \mathrm{g} / \mathrm{ml}$ (Fig. 2, lower graph, Peak B). During this period, TCI was evacuated. If TCI runs into the mainstream, the $\mathrm{C}_{\text {eff }}$ would be over-shot after fill-up bolus, and if TCI stops, TCI could not harmonize with the status of predicted concentrations when the brand correction started. Afterwards, the syringe brand was corrected (Fig. 2, lower graph, Peak C).

The median maintenance $\mathrm{C}_{\text {eff }}$ of TERUMO $\mathrm{BDP}_{\mathrm{BD}}$ was $4.78 \mu \mathrm{g} / \mathrm{ml}$. During the steady state of TCI, context sensitive decrement time (Csdt) at a certain time was known to be constant, regardless of concentration [7]. Therefore, Csdt of $16.32 \%$ (4.78 to $4.0 \mu \mathrm{g}$ / $\mathrm{ml})$ will be same as that of 4.0 to $3.35 \mu \mathrm{g} / \mathrm{ml}(4.78: 4.0=4.0$ : 3.35). Most of the TCI have the function of Csdt estimation. The software of this study showed $1.84 \mathrm{~min}$ as a return value when $3.35 \mu \mathrm{g} / \mathrm{ml}$ was entered into ' $\mathrm{C}_{\text {eff-awake }}$ ' function. Therefore, we determined the evacuation time to be $110 \mathrm{sec}$. The Csdt of $16.32 \%$ at $30 \mathrm{~min}$ was also $110.7 \mathrm{sec}$, as calculated using the 'CsdtCe' library of PKPD Tools for Excel (available at the website, http://pkpdtools.com, in April, 2012).

We estimated the correction amount and the duration of evacuation based on the maintained TCI. However, the PK model was not a one-compartment model, but a three-compartment model. TCI simulations showed different time courses of the concentrations of the compartments; $\mathrm{Cl}$ (central compartment, $\mathrm{C}_{\mathrm{p}}$ ), C2, and C3 (rapid and slow peripheral compartments) (Fig. 4). Wrong TCI erroneously estimated C2 and C3, as well as $\mathrm{C}_{\mathrm{p}}$, and this might be a principal reason for minor deviations, during or after brand corrections. During the correction of $\mathrm{BDP}_{\text {TeRumo, }}$ the concentration gradient between C1and C2 during targeting $4.0 \mu \mathrm{g} / \mathrm{ml}$ was greater than that of targeting 3.31 $\mu \mathrm{g} / \mathrm{ml}$. Therefore, the amount of bolus needed to increase the values from 4.0 to $4.69 \mu \mathrm{g} / \mathrm{ml}$ was $1.2 \pm 0.1 \mathrm{mg}$ greater than that of 3.31 to $4.0 \mu \mathrm{g} / \mathrm{ml}$. However, the overshoot was only $1.5 \%$ of $\mathrm{C}_{\text {eff }}$. In addition, after the brand correction, the wrong TCI was also over-predicting C2 and C3 (Fig. 4, upper graph). Thereby, the maintaining infusion rates were insufficient to maintain the target, so the actual concentration showed a slight decrease,

Table 3. Simple and Active Correction for the $\mathrm{BDP}_{\text {TERUM }}$ and $\mathrm{TERUMO}_{\mathrm{BDP}}$ Targeting Effect-site Concentration of Propofol, and Time to Reach $\pm 5 \%$ of Target

\begin{tabular}{|c|c|c|c|c|c|c|}
\hline & \multicolumn{2}{|c|}{$\mathrm{BDP}_{\text {TERUMO }}$} & \multirow[b]{2}{*}{$P$ value } & \multicolumn{2}{|c|}{ TERUMO $_{\mathrm{BDP}}$} & \multirow[b]{2}{*}{$P$ value } \\
\hline & $\begin{array}{l}\text { Simple } \\
(\mathrm{n}=12)\end{array}$ & $\begin{array}{c}\text { Active } \\
(\mathrm{n}=12)\end{array}$ & & $\begin{array}{l}\text { Simple } \\
(\mathrm{n}=12)\end{array}$ & $\begin{array}{l}\text { Active } \\
(\mathrm{n}=12)\end{array}$ & \\
\hline $\mathrm{C}_{\text {eff }}$ at $30 \mathrm{~min}(\mu \mathrm{g} / \mathrm{ml})$ & $3.31 \pm 0.01$ & $3.31 \pm 0.01$ & 0.584 & $4.76 \pm 0.01$ & $4.76 \pm 0.02$ & 0.857 \\
\hline $\mathrm{T}_{ \pm 5 \% \text { target }}(\mathrm{min})$ & $21.7 \pm 2.3$ & $4.1 \pm 0.6$ & $<0.001$ & $15.9 \pm 0.9$ & $4.9 \pm 0.6$ & $<0.001$ \\
\hline Fill-up bolus (mg) & - & $23.4 \pm 3.7$ & & - & - & \\
\hline Evacuation amount (mg) & - & - & & - & $23.1 \pm 3.2$ & \\
\hline
\end{tabular}

Values indicate mean \pm SD. BDP $_{\text {TERUMO }}$ : $\mathrm{BD}$ Plastipak syringe with false setting to Terumo, $\mathrm{TERUMO}_{\mathrm{BDP}}$ : Terumo syringe with false setting to BDP, $\mathrm{C}_{\text {eff }}$ : effect-site concentration, $\mathrm{T}_{ \pm 5 \% \text { target }}$ : time to reach $\pm 5 \%$ of target. 

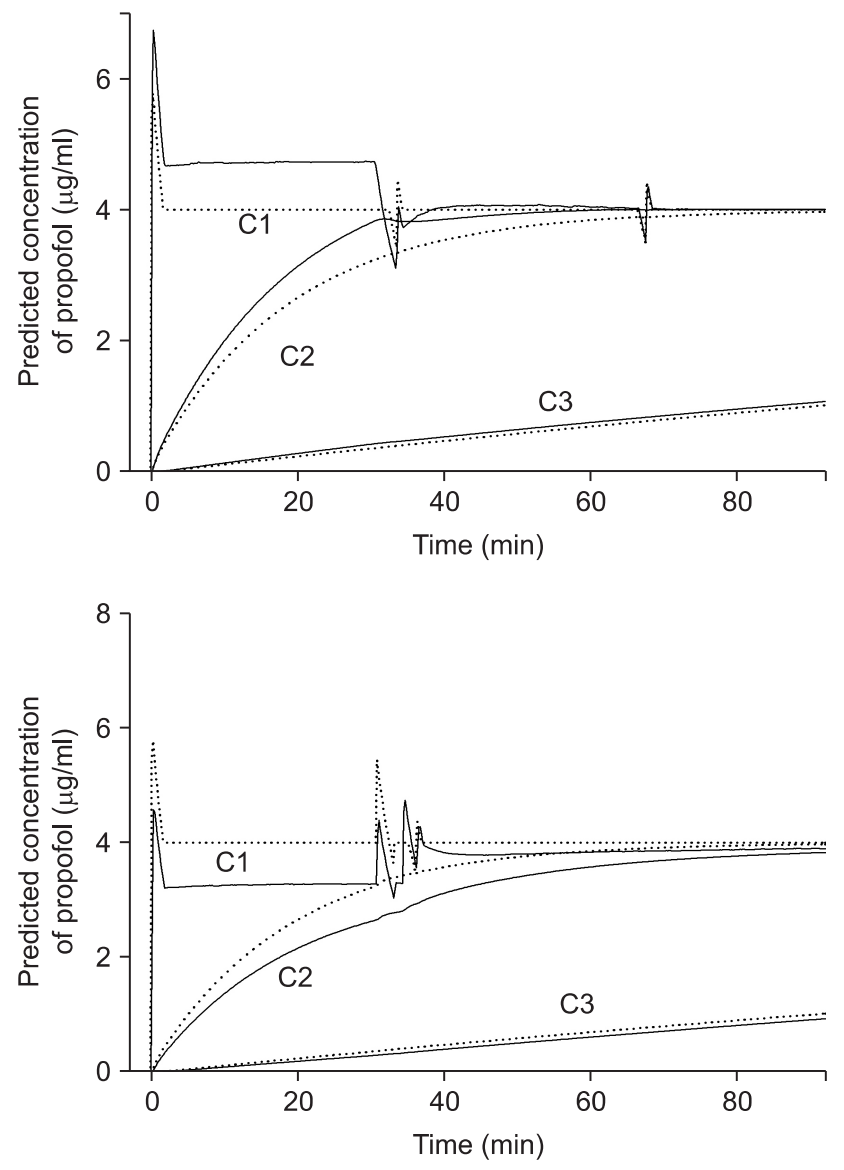

Fig. 4. The nominal (dotted lines) and reproduced actual (solid lines) predicted plasma concentrations of propofol at the central compartment, $\mathrm{Cl}$ (upper), and at two peripheral compartments, C2 (middle), and C3 (lower) targeting $4.0 \mu \mathrm{g} / \mathrm{ml}$ of effect-site concentration, and the active corrections were performed for the BDP with false setting to TERUMO (upper graph) and the TERUMO with false setting to BDP (lower graph).

and then slowly normalized to the target. However, during TCI, it would be impossible to correct the infusion rate, considering C2 and C3. Nevertheless, the actual concentrations were hardly deviated more than $5 \%$ of target. Conversely, after correction of TERUMO $_{\mathrm{BDF}}$, the wrong TCI also under-predicted C2 and C3 (Fig. 4, lower graph), so the actual concentration showed a slight increase, and then gradually approached the target.

When we increased the target concentration, TCI targeting effect-site infused drug as a bolus pattern, and subsequently stopped the infusion. Therefore, targeting effect-site might be useful for the fill-up correction, because the fill-up bolus is easily calculated from the display window. On the contrary, targeting plasma might be more helpful for the evacuation correction. After cessation of TCI, $\mathrm{C}_{\mathrm{p}}$ falls faster than $\mathrm{C}_{\text {eff }}$, and the Csdt of the effect-site is longer than that of plasma [8]. Therefore, at the moment of the start of the brand correction, it was not an equilibrium state. However, targeting plasma will never miss the decrease in $\mathrm{C}_{\mathrm{p}}$ after Csdt of the plasma. The software used in this study was incapable of switching over the modes between targeting plasma and effect-site during the infusion. When this switching mode is available, it would be better to switch to more effective modes before the correction. However, Csdt displayed in the software must be checked out to ensure its suitability for either the plasma or the effect-site.

There are some caveats to be discussed here. First, in some syringe pumps, brand selection cannot be changed during operating periods. In these cases, the erroneously placed syringe should be replaced with a syringe of correct compatibility. Second, after the test increase during the fill-up correction, we performed next step after achieving the equilibrium state. However, each process could be performed consecutively, while each peak (Fig. 2, lower graph, Peak B and C) might override on the previous peak (Fig. 2, lower graph, Peak A), and it could decrease the duration of correction; however, $\mathrm{C}_{\text {eff }}$ could show an excessive increase.

We compared brand-specific volumetric differences of various syringe brands compatibilities, and their impacts on TCI of propofol during false setting of brand. Careful efforts with vigilance are always needed at the start of TCI. However, if we know how to handle a potential error situation in advance, we might easily cope up with the situation, without giving up the wrong TCI, using the methods based on the pharmacokinetic and pharmacodynamic characteristics of propofol.

\section{References}

1. Neff T, Fischer J, Fehr S, Baenziger O, Weiss M. Evaluation of the FASTSTART mode for reducing start-up delay in syringe pump infusion systems. Swiss Med Wkly 2001; 131: 219-22.

2. Weiss M, Gerber S, Füchslin RM, Neff TA. Accurate continuous drug delivery at low infusion rate with a novel microvolumetric infusion pump (MVIP): pump design, evaluation and comparison to the current standard. Anaesthesia 2004; 59: 1133-7.

3. Gray JM, Kenny GN. Development of the technology for 'Diprifusor' TCI systems. Anaesthesia 1998; 53 Suppl 1: 22-7.

4. Neff T, Fischer J, Fehr S, Baenziger O, Weiss M. Start-up delays of infusion syringe pumps. Paediatr Anaesth 2001; 11: 561-5.

5. Gepts E, Camu F, Cockshott ID, Douglas EJ. Disposition of propofol administered as constant rate intravenous infusions in humans. Anesth Analg 1987; 66: 1256-63.

6. Struys MM, De Smet T, Depoorter B, Versichelen LF, Mortier EP, Dumortier FJ, et al. Comparison of plasma compartment versus two methods for effect compartment--controlled target-controlled infusion for propofol. Anesthesiology 2000; 92: 399-406.

7. Hughes MA, Glass PS, Jacobs JR. Context-sensitive half-time in multicompartment pharmacokinetic models for intravenous anesthetic drugs. Anesthesiology 1992; 76: 334-41.

8. Shafer SL, Varvel JR. Pharmacokinetics, pharmacodynamics, and rational opioid selection. Anesthesiology 1991; 74: 53-63. 